\title{
Establishing an Anemia Clinic for Optimal Erythropoietic-Stimulating Agent Use in Hematology-Oncology Patients
}

Jeffrey A. Gilreath, PharmD; Daniel S. Sageser, PharmD; James A. Jorgenson, RPh, MS; and George M. Rodgers, MD, PhD, , Salt Lake City, Utah

\section{Key Words}

Anemia, clinic, cancer, erythropoietic-stimulating agent, algorithm, chemotherapy

\begin{abstract}
Erythropoietic-stimulating agent (ESA) therapy has significantly impacted the management of chemotherapy-induced anemia ( $\mathrm{Cl} A$ ) by decreasing the number of red blood cell transfusions required by patients with cancer. However, managing these patients with ESA therapy has become increasingly difficult since the release of the Centers for Medicare \& Medicaid Services' new National Coverage Determination document because of the disparities between this document and recommendations from expert-reviewed national clinical guidelines on the treatment of anemia. This article describes a collaborative practice agreement between pharmacists and physicians as one approach to managing $\mathrm{ClA}$ in hematology-oncology patients in an anemia clinic. The goal of the pharmacist-managed anemia clinic is to improve patient satisfaction and clinical outcomes associated with the treatment of $\mathrm{CIA}$. This article describes the rationale for the clinic and discusses its design and implementation in managing ESA, iron, folate, and vitamin $B_{12}$ therapy for $\mathrm{CI} A$ in hematology-oncology patients. The pharmacist's role is justified in this clinic model through increased adherence to evidence-based practice guidelines and decreased costs associated with ESA therapy. (JNCCN 2008;6:577-584)
\end{abstract}

From ${ }^{a}$ Huntsman Cancer Institute, Department of Pharmacy Services, University of Utah Hospitals and Clinics; ' University of Utah Hospitals and Clinics; and 'Departments of Medicine and Pathology, Huntsman Cancer Institute, University of Utah Health Sciences Center, Salt Lake City, Utah.

Submitted January 1, 2008; accepted for publication April 22, 2008. Dr. Gilreath participated on an advisory board for University Pharmacotherapy Associates. Dr. Sageser has no financial interest, arrangement, or affiliation with the manufacturers of any products discussed in the article or their competitors. Mr. Jorgenson has participated on advisory boards for Ortho Biotech and Amgen. Dr. Rodgers served as a consultant and provided clinical trial support for Amgen and has participated on Amgen speakers' bureau. Correspondence: Jeffrey A. Gilreath, PharmD, Huntsman Cancer Institute, 1950 Circle of Hope, Suite 2110, Salt Lake City, UT 84112. E-mail: jeffrey.gilreath@hci.utah.edu

\section{Cancer- and Chemotherapy-Induced Anemia}

Anemia is a common consequence of cancer and its treatment. Data from the European Cancer Anaemia Survey (ECAS), which studied approximately 15,000 patients with cancer, showed that the prevalence of anemia is roughly $30 \%$ in untreated patients. When chemotherapy is given, the prevalence of anemia increases to approximately $60 \%$ for all malignancies combined. ${ }^{1}$ Despite the high prevalence of anemia among hematology-oncology patients, many remain untreated. For the purposes of this clinic, patients with chemotherapy-induced anemia (CIA) were defined as those who have undergone myelosuppressive chemotherapy within the past 6 weeks and who are symptomatic with a hemoglobin $(\mathrm{Hb})$ level less than $11 \mathrm{~g} / \mathrm{dL}$ or asymptomatic with a $\mathrm{Hb}$ of $10 \mathrm{~g} / \mathrm{dL}$ or less. ${ }^{2}$

Treatment options to correct anemia in cancer patients $(\mathrm{Hb}<12 \mathrm{~g} / \mathrm{dL})$ include red blood cell transfusions, erythropoietic-stimulating agent (ESA) therapy, and iron, folic acid, and vitamin $B_{12}$ supplementation. ${ }^{2}$ The results of clinical trials confirm that ESAs, in patients with iron, folate, and vitamin $B_{12}$ repletion, significantly reduce the need for blood transfusions, and reliably increase $\mathrm{Hb}$ levels for patients with CIA. ${ }^{3-11}$ For anemic patients not undergoing chemotherapy, recognizing the exact causes of anemia and treating it appropriately is important.

\section{Usefulness of Intravenous Iron}

The results of multiple open-label, multicenter, randomized trials in patients with cancer indicate that intravenous (IV) iron should now be considered standard care for repleting and maintaining adequate iron stores in functionally iron-deficient patients undergoing ESA therapy.,3,12-14 Auerbach et al. ${ }^{3}$ showed that IV iron dextran total-dose 
Gilreath et al.

infusion led to a statistically significant mean increase in $\mathrm{Hb}$ of $2.4 \mathrm{~g} / \mathrm{dL}$ from baseline, compared with only 1.5 and $0.9 \mathrm{~g} / \mathrm{dL}$ increase from baseline when using oral ferrous sulfate or no iron repletion, respectively.

Henry et al. ${ }^{4}$ presented similar results using IV sodium ferric gluconate in patients with CIA who were iron-replete at baseline (serum ferritin $\geq 100$ $\mathrm{ng} / \mathrm{mL}$, transferrin saturation [TSAT] $\geq 15 \%$ ). These studies, along with others, ${ }^{12-14}$ show that appropriate iron repletion increases response rates to ESAs while reducing the need for higher doses of ESA therapy. In light of recently published survival data that question whether ESAs stimulate tumor growth, IV iron repletion has gained even greater importance in the treatment of patients with cancer- and chemotherapyinduced anemia. ${ }^{15}$ In contrast to functional iron-deficiency anemia, clinicians should continue to treat absolute iron-deficiency anemia (serum ferritin $<30$ $\mathrm{ng} / \mathrm{mL}$ and TSAT $<15 \%)$ in patients with cancer with IV or oral iron and await response before initiating ESA therapy.

\section{Blood Supply}

The decision of the Centers for Medicare \& Medicaid Services (CMS) to restrict ESA use to Medicare/ Medicaid patients with an $\mathrm{Hb}$ of less than $10 \mathrm{~g} / \mathrm{dL}$ may be increasing the incidence of transfusions required by hematology-oncology patients. Shifts in blood use have already been observed in national databases.

The Premier Perspective Comparative Database includes more than 380 hospitals and data from 78,000 to 93,000 cancer discharges per quarter from 98 continuously reporting hospitals. These data, when comparing the third quarter of 2007 to the same period in 2006, show that the number of Medicare/Medicaid recipients with cancer who received transfusions increased by $13 \% .{ }^{16}$ Although these data cannot establish that transfusion rates are increasing as a direct result of CMS' actions, the rate of transfusions is nonetheless increasing in this population. Instead of adopting the CMS standard for everyone, a 2-tiered ESA treatment algorithm, targeting an $\mathrm{Hb}$ level of 11 to $11.9 \mathrm{~g} / \mathrm{dL}$ for privately insured patients and a $\mathrm{Hb}$ less than $10 \mathrm{~g} / \mathrm{dL}$ for CMS-covered patients, may help preserve the nation's blood supply.

\section{Anemia Clinic: A Standardized Approach}

The need for a standardized approach to managing CIA arises from the difficulty of ESA monitoring and enigmatic reimbursement issues surrounding their use. Problems with current management include 1) using ESA therapy outside of package insert and clinical guideline recommendations, which has become increasingly important because of data suggesting an increase in adverse events and potential decrease in overall survival in cancer patients not undergoing chemotherapy; ${ }^{17-21} 2$ ) using ESAs in iron, folate, or vitamin $\mathrm{B}_{12}$-deficient individuals; 3 ) lack of dose escalation, de-escalation, or discontinuation of ESA therapy when indicated, and 4) using ESA therapy without documenting appropriate information required for proper coding, billing, and reimbursement. The implementation of a pharmacist-managed anemia clinic is designed to address these problems.

\section{Internal Audit}

An internal audit exploring the cost-effectiveness of ESA therapy and patient outcomes at the University of Utah found that physicians were not appropriately monitoring the use of these agents.

The study involved a 52-patient retrospective chart review examining the management of patients treated with either epoetin alfa or darbepoetin alfa over a 12-week period. At baseline, the study found that iron stores were not assessed in roughly $70 \%$ of patients. At week 4, a recommended ESA dosage increase was prescribed for only $6 \%(2 / 32)$ of patients for whom it was indicated, and at week $12,58 \%(30 / 52)$ of patients were continued on subtherapeutic ESA therapy $(\mathrm{Hb}$ increase $<1 \mathrm{~g} / \mathrm{dL}){ }^{2,22}$ The results of this study suggested that a standardized approach in managing hematology-oncology patients receiving ESAs could be improved by more closely monitoring iron status and ESA therapy.

\section{Creation and Implementation}

The anemia clinic was created to standardize the management of ESA, iron, and B-vitamin therapy for CIA at the authors' institution. The model discussed by Kuo et al..$^{23}$ was used as the initial approach to constructing the clinic.

\section{Physician Versus Pharmacist Management}

The model of anticoagulation clinics in which pharmacists manage oral anticoagulation therapy under physician supervision provides a paradigm to improve anemia management for hematology-oncology patients. ${ }^{24,25}$ Much like monitoring anticoagulation therapy, a dedicated practitioner will spend more time managing medications related to anemia in hopes of 
Establishing Anemia Clinic for Hematology-Oncology Patients

consistently achieving and maintaining patients' $\mathrm{Hb}$ levels within the targeted range. ${ }^{26}$

Implementation of a pharmacist-managed anemia clinic will likely decrease physician workload, allowing physicians more time for other patient care activities. In addition, the anemia clinic will ensure that other contributing factors (deficiencies of iron, folate, vitamin $B_{12}$ ) have been excluded before beginning, and during, ESA therapy. Pharmacists will still provide supplemental patient education to improve patient compliance.

Timely and appropriate documentation of pharmacist-provided services assures that physicians remain well informed of patient progress. In addition, reimbursement rates should increase as a result of consistently providing all necessary information to medical coders. In light of recent clinical data and controversy about ESA therapy targeting a $\mathrm{Hb}$ of 12 $\mathrm{g} / \mathrm{dL}$ or more, ${ }^{17-21}$ strict adherence to national guidelines and package insert recommendations may decrease adverse events. Furthermore, subtherapeutic doses of ESAs will be reduced or eliminated.

\section{Business Plan/Financial Justification}

Given the current fiscal pressure hospitals face, the cost of a pharmacist managing these agents must be justified with a business plan. The authors' organization focused on the incremental value this model would produce compared with the existing physician-driven model. Efforts to improve the finances surrounding ESA therapy management center on the pharmacist's ability to effectively prevent and recover payment denials for ESAs.

As the authors began to build order templates, they established a rapport with the coding, accounting, and compliance teams to ensure that all required elements were documented to increase the likelihood of up-front payment. The coders indicated that many claims were submitted without the correct diagnosis code, often because of the absence of supporting laboratory values or vague documentation of the cause of the patients' anemia. Coders were receiving denied claims of which providers were unaware, and the communication necessary to resolve these discrepancies was lacking between these groups.

The authors' anemia clinic pharmacist began contacting prescribers to request that they obtain the required laboratory values before prescribing further ESA therapy. The authors estimated that the potential net revenue gain from 12 months of more accu- rately and appropriately submitted claims should generate the funds necessary to justify hiring a full-time pharmacist to operate the clinic. After determining a benefit-to-cost ratio of $3: 1$, they made a strong financial justification for their program. State-specific laws on the use of collaborative practice agreements between physicians and pharmacists must be researched before developing any other portion of a pharmacistmanaged anemia clinic. ${ }^{23}$

\section{Collaborative Practice Agreement, Treatment Algorithm, and Template}

The first 3 steps taken to structure the anemia clinic were to construct a collaborative practice agreement, treatment algorithm, and template. With the help of the clinic's medical director, the collaborative practice agreement was constructed to clearly define the scope of the pharmacist's interventions in the specific patient population. It was approved by the University of Utah Pharmacy and Therapeutics committee and allows the anemia clinic pharmacist to use the treatment algorithm (Figure 1) and order template (Figure 2) to treat patients with CIA. The major focus of the algorithm is to ensure that 1) patients undergoing ESA therapy have an appropriate indication for ESA use, 2) iron, vitamin $B_{12}$, and folate deficiencies are appropriately managed, and 3) optimal ESA therapy is used (e.g., dose escalation, cessation of therapy for patients not experiencing response). After reviewing the literature and finding no standardized approach to vitamin $\mathrm{B}_{12}$ and folate repletion in hematology-oncology patients, the authors extrapolated data from other patient populations in an attempt to standardize B-vitamin supplementation. ${ }^{40-43}$ Lastly, they developed a medication order template to standardize the ordering of ESAs and appropriate laboratory tests, and capture all required information for submitting a complete claim.

\section{Process and Workflow}

The anemia clinic, piloted by a pharmacist, is located in the hematology-oncology clinic. In addition to managing ESA therapy, the pharmacist is available for consultation on other drug-related issues. Therefore, having a pharmacist specially trained in hematology-oncology to staff the clinic is ideal.

Patients are referred by physicians to participate and must be diagnosed with CIA to have the referral accepted. The pharmacist inquires about payment issues and thoroughly reviews the patient's medications and medical record before each visit. The pharmacist tries to consolidate clinic visits by scheduling 
Gilreath et al.

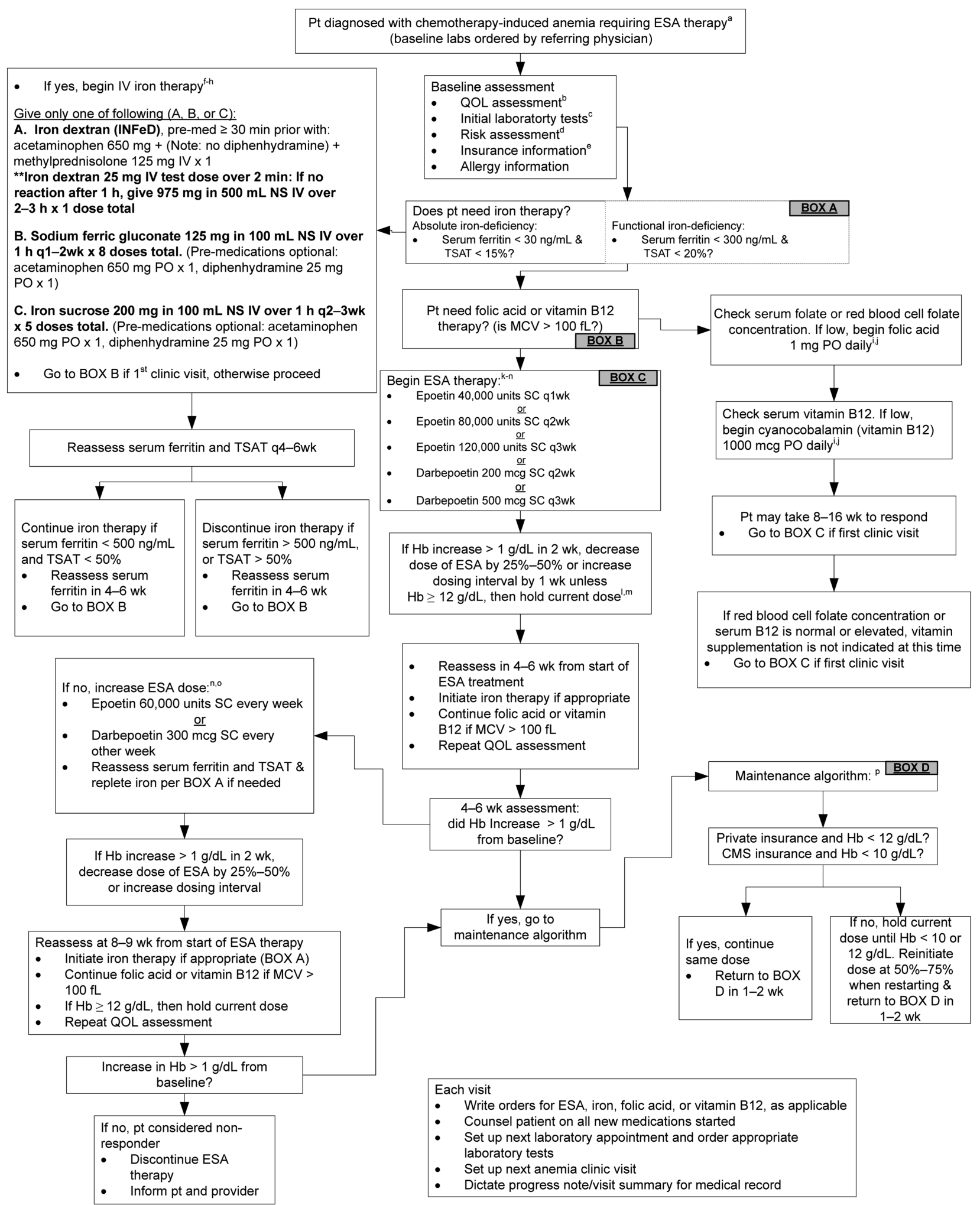

Figure 1 Anemia clinic treatment algorithm. Patients enrolled in the clinic receive a baseline evaluation, including assessment of iron and vitamin stores, with appropriate repletion before ESA therapy initiation. Patients are monitored regularly to ensure compliance with guidelines and insurance regulations. Abbreviations: ESA, erythropoietic stimulating agent; CMS, Centers for Medicare \& Medicaid Services; Hb, hemoglobin; IV, intravenous; mcg, micrograms; $\mathrm{MCV}$, mean corpuscular volume; NS, normal saline; PO, by mouth; QOL, quality of life; pt, patient; SC, subcutaneously; TSAT, transferrin saturation. See next page to view notes from the algorithm. 
Establishing Anemia Clinic for Hematology-Oncology Patients

\section{Collaborative Anemia Management Protocol (Notes from Algorithm)}

a) Anemia defined as $\mathrm{Hb} \leq 11 \mathrm{~g} / \mathrm{dL}$ in symptomatic patients and $<10$ $\mathrm{g} / \mathrm{dL}$ in asymptomatic patients. ESA therapy to be given only to patients with nonmyeloid malignancies undergoing chemotherapy (e.g., breast, lung, gynecologic). Target Hb level: 11-12 g/dL. 2,10,11 Do not give an ESA to a patient with an $\mathrm{Hb} \geq 12 \mathrm{~g} / \mathrm{dL}$.

b) The Linear Analog Scale Assessment (LASA) and Functional Assessment of Cancer Therapy-Anemia (FACT-An) assessment scales. ${ }^{27-29}$

c) Review and record all applicable laboratory values on monitoring form. ${ }^{30}$ A patient medication profile review and medication reconciliation must be completed before dispensing any new medications.

d) Risk assessment: mild anemia, $\mathrm{Hb} 10-11 \mathrm{~g} / \mathrm{dL}$; moderate anemia, $\mathrm{Hb} 8-10 \mathrm{~g} / \mathrm{dL}$; severe anemia, $\mathrm{Hb}<8 \mathrm{~g} / \mathrm{dL}$. Inform physician if $\mathrm{Hb}<8$ $\mathrm{g} / \mathrm{dL}$ and await instruction. If immediate transfusion not required, continue with algorithm. The physician must be notified if evidence of bleeding is present; patient has uncontrolled hypertension; patient experiences a sudden loss of response to ESA therapy accompanied by severe anemia and a low reticulocyte count (pure red cell aplasia); or patient has a suspected thrombotic event, a new onset seizure, or evidence of iron overload (jaundice, increasing liver function tests, or bilirubin)..$^{10,11,29,31}$ Risks and benefits of ESA therapy versus transfusion are discussed at the initial visit.

e) Insurance assessment (if prior authorization has not been obtained). Both Amgen and Ortho Biotech have patient assistance programs (PAP) for patients who do not have third-party insurance.

f) If patient received red blood cell transfusion within last 30 days, hold iron therapy for 30 days after the date of the blood transfusion and proceed with algorithm. Redraw serum ferritin and TSAT within 30 days of red blood cell transfusion. If no blood given within 30 days, proceed with algorithm.

g) Patient considered iron-deficient and requiring iron replacement if serum ferritin $<30 \mathrm{ng} / \mathrm{mL}$ and TSAT $<15 \%$, or serum ferritin $<300$ $\mathrm{ng} / \mathrm{mL}$ and TSAT $<20 \%$ and patient is undergoing ESA therapy. ${ }^{2-4,32}$

h) Iron supplementation is required for most patients undergoing ESA therapy; however, optimal maintenance serum ferritin and TSAT levels have not been established. Ultimate goal of iron therapy is to support ESA-stimulated erythropoiesis and maintain target $\mathrm{Hb}$ levels, not to achieve a particular level of serum ferritin or TSAT. To maintain erythropoiesis: TSAT $>20 \%$ but $<50 \%$, and serum

anemia appointments that coincide with regular clinic appointments.

During the initial visit, the pharmacist discusses the purpose of the clinic and completes a medication reconciliation and then uses the algorithm to order and review the appropriate laboratory tests (see Notes from Algorithm). After assessing patients for signs and symptoms related to anemia and its treatment, the pharmacist prescribes medication, when clinically warranted, using the template shown in Figure 2. The pharmacist then records all information in the chart and counsels the patient about the drug therapy, including risks and benefits of ESA therapy versus trans- ferritin $>100 \mathrm{ng} / \mathrm{mL}$ but $<500 \mathrm{ng} / \mathrm{mL}{ }^{32}$ If no contraindications to iron therapy (hypersensitivity to IV iron products or evidence of iron overload), administer iron dextran (INFeD) total dose infusion (maximum: $1000 \mathrm{mg}$ per dose).,33-35 Make sure to give test dose and premedicate. ${ }^{33}$ Alternatives: sodium ferric gluconate (Ferrlecit) $125 \mathrm{mg}$ intravenously every $1-2$ weeks $\times 8$ doses total, ${ }^{4,36}$ or iron sucrose (Venofer) $200 \mathrm{mg}$ intravenously over 1 hour every 2-3 weeks $\times 5$ doses total..$^{37,38}$ Oral iron should not be used for initial iron repletion because it does not provide iron quickly enough to support the accelerated erythropoiesis that occurs with ESA therapy. ${ }^{3.4}$ Do not use intravenous iron therapy for patients with signs or symptoms of infection. ${ }^{39,40}$ Do not use Dexferrum.

i) Folic acid: patients treated with folic acid for a deficiency may benefit with a decrease in ESA dose, increase in $\mathrm{Hb}$ response, and a decrease in overall cost of ESA therapy. The peak hematological response to folic acid therapy may take as long as 6-8 weeks, and greatest impact is usually seen with prolonged treatment. ${ }^{41-43}$ Red blood cell folate is better for testing long-standing folate deficiency.

j) Vitamin $B_{12}$ : patients treated with vitamin $B_{12}$ for a deficiency may benefit with decreased ESA dose, increased $\mathrm{Hb}$ response, and decreased overall cost of ESA therapy. Oral vitamin $B_{12}$ in dosages of $\geq 1,000 \mu \mathrm{g} / \mathrm{d}$ has been shown to significantly increase serum $B_{12}$ levels to a greater extent than intramuscular vitamin $\mathrm{B}_{12}{ }^{43,44}$

k) If patient's $\mathrm{Hb} \leq 11 \mathrm{~g} / \mathrm{dL}$ and symptomatic or $\leq 10 \mathrm{~g} / \mathrm{dL}$ and asymptomatic, give epoetin or darbepoetin to maintain $\mathrm{Hb}$ between 11-12 $\mathrm{g} / \mathrm{dL} .^{2,10,11}$

1) ESA adjustment: if $\mathrm{Hb}$ rises $>1 \mathrm{~g} / \mathrm{dL}$ in a 2 -week period, reduce dose by $25 \%-50 \%$ (round to nearest vial or syringe size). Recheck $\mathrm{Hb}$ in 1-2 weeks. ${ }^{2,10,11}$

m) ESA adjustment: if $\mathrm{Hb} \geq 12 \mathrm{~g} / \mathrm{dL}$, hold dose until $\mathrm{Hb}<12 \mathrm{~g} / \mathrm{dL}$, then reinitiate dose at $50 \%-75 \%$ when restarting. Reassess $\mathrm{Hb}$ response in 1-2 weeks. ${ }^{2,10,11}$

n) ESA adjustment: if $\mathrm{Hb}$ increase $<1 \mathrm{~g} / \mathrm{dL}$ from baseline at 4-6 weeks, and $<12 \mathrm{~g} / \mathrm{dL}$, increase dose of epoetin or darbepoetin according to algorithm. . $10,11^{2}$

o) No dose escalation guidelines available for the following starting regimens: epoetin $80,000 \mathrm{U}$ subcutaneously every other week, epoetin 120,000 U subcutaneously every 3 weeks, or darbepoetin $500 \mu g$ subcutaneously every 3 weeks. ${ }^{2,10,11}$

p) Discontinue ESA after chemotherapy is complete and anemia has resolved. This usually occurs 6-8 weeks after cessation of myelosuppressive chemotherapy. ${ }^{2,10,11}$

fusion. Lastly, the pharmacist records and documents test results, drug dosing, and any adverse events resulting from drug therapy. This process is outlined in Figure 3. Recommendations not outlined in the protocol require approval of the referring physician.

\section{Advantages of the Clinic Model}

The anemia clinic creates the structure needed to improve clinical outcomes. A successful anemia clinic will also optimize reimbursement for ESAs, an expensive class of drugs. For patients not referred to the anemia clinic, implementation of an ESA-specific order template still provides the coding team the necessary information to submit a complete insurance claim. In 
Week

\section{Chemotherapy-Induced Anemia}

\section{A. Required Laboratory Tests:}

1. $\mathrm{CBC}$ (within 1 week of initial injection)

2. TSAT \& serum ferritin (before first dose of ESA to rule out deficiency)

3. Serum vitamin $B_{12}$ (before first dose of ESA to rule out deficiency)

4. Serum folate or red blood cell folate concentration (before first dose of ESA to rule out deficiency)

\section{B. Chemotherapy-Induced Anemia for Chemotherapy Given Within the Past 6-8 Weeks:}

1. Replete iron as indicated

2. Tumor type: lymphocytic leukemia) (i.e., type of solid tumor, multiple myeloma, lymphoma, or

3. Chemotherapy agents contributing to anemia:

4. Last dose of chemotherapy:

5. Ensure that patient does not have uncontrolled hypertension, a myeloid malignancy, bone marrow fibrosis, or a known hypersensitivity to erythropoietin, darbepoetin, or any of the excipients

\section{Erythropoietic Stimulating Agent Orders:}

\section{Darbepoetin alfa (Aranesp) ___ $\mu \mathrm{g}$ subcutaneously $q \ldots$ wk $x$}

(Round dose down to nearest: $25 \mathrm{mcg}, 40 \mathrm{mcg}, 60 \mathrm{mcg}, 100 \mathrm{mcg}, 150 \mathrm{mcg}, 200 \mathrm{mcg}, 300 \mathrm{mcg}$, or $500 \mathrm{mcg}$ )

${ }^{* * O R^{* *}}$

2. Epoetin alfa (Procrit/Epogen) _ units subcutaneously $\mathbf{q}$ wk x (Round dose down to nearest: $3,000 \mathrm{U} ; 4,000 \mathrm{U} ; 10,000 \mathrm{U}$; or 40,000 U)

\section{(NCCN Guideline) Dosing May Begin When Hemoglobin is $<11 \mathrm{~g} / \mathrm{dL}$}

1. Check CBC every 1-2 wk (or at next scheduled chemotherapy appointment):

- If $\mathrm{Hb}<11 \mathrm{~g} / \mathrm{dL}$ and rise in $\mathrm{Hb}$ is $>1 \mathrm{~g} / \mathrm{dL}$ : decrease dose by $25 \%$

- If $\mathrm{Hb}<11 \mathrm{~g} / \mathrm{dL}$ and rise in $\mathrm{Hb}$ is $<1 \mathrm{~g} / \mathrm{dL}$ : continue starting dose $\times 4$ wk total for epoetin, or 6 wk total for darbepoetin, then if $\mathrm{Hb}<11 \mathrm{~g} / \mathrm{dL}$ and rise in $\mathrm{Hb}$ is $<1 \mathrm{~g} / \mathrm{dL}$ : increase dose by $50 \%$

2. If $\mathrm{Hb}$ is ever $\geq 12 \mathrm{~g} / \mathrm{dL}$ : hold next dose

- When $\mathrm{Hb}$ falls to $11-11.9 \mathrm{~g} / \mathrm{dL}$, restart at $25 \%$ dose reduction from prior dose to maintain $\mathrm{Hb}$ between $11-11.9 \mathrm{~g} / \mathrm{dL}$

3. Discontinue ESA after $\underline{8-9} \mathrm{wk}$ if no response to either agent (if $\mathrm{Hb}$ fails to rise $>1 \mathrm{~g} / \mathrm{dL}$ from baseline)

\section{(Medicare Guideline) Dosing May Begin When Hemoglobin is $<10 \mathrm{~g} / \mathrm{dL}$}

1. Check CBC every 1-2 wk (or next scheduled chemotherapy appointment):

- If $\mathrm{Hb}<10 \mathrm{~g} / \mathrm{dL}$ and rise in $\mathrm{Hb}$ is $>1 \mathrm{~g} / \mathrm{dL}$ : decrease dose by $25 \%$

- If $\mathrm{Hb}<10 \mathrm{~g} / \mathrm{dL}$ and rise in $\mathrm{Hb}$ is $<1 \mathrm{~g} / \mathrm{dL}$ : continue starting dose $\times 4$ wk total for epoetin, or 6 wk darbepoetin, then if $\mathrm{Hb}<10 \mathrm{~g} / \mathrm{dL}$ and rise in $\mathrm{Hb}$ is $<1 \mathrm{~g} / \mathrm{dL}$ : increase dose by $50 \%$

2. If $\mathrm{Hb}$ is ever $>10 \mathrm{~g} / \mathrm{dL}$ : hold next dose

- When $\mathrm{Hb}$ falls to $9-10 \mathrm{~g} / \mathrm{dL}$, restart at 25\% dose reduction from starting dose to maintain Hb between 9 and $10 \mathrm{~g} / \mathrm{dL}$

3. Discontinue ESA after $\underline{8-9} \mathrm{wk}$ if no response to either agent (if $\mathrm{Hb}$ fails to rise $>1 \mathrm{~g} / \mathrm{dL}$ from baseline)

Figure 2 Chemotherapy-induced anemia (CIA) template.

Abbreviations: CBC, complete blood count; ESA, erythropoietic stimulating agent; Hb, hemoglobin; mcg, microgram; TSAT, transferrin saturation. 
Establishing Anemia Clinic for Hematology-Oncology Patients

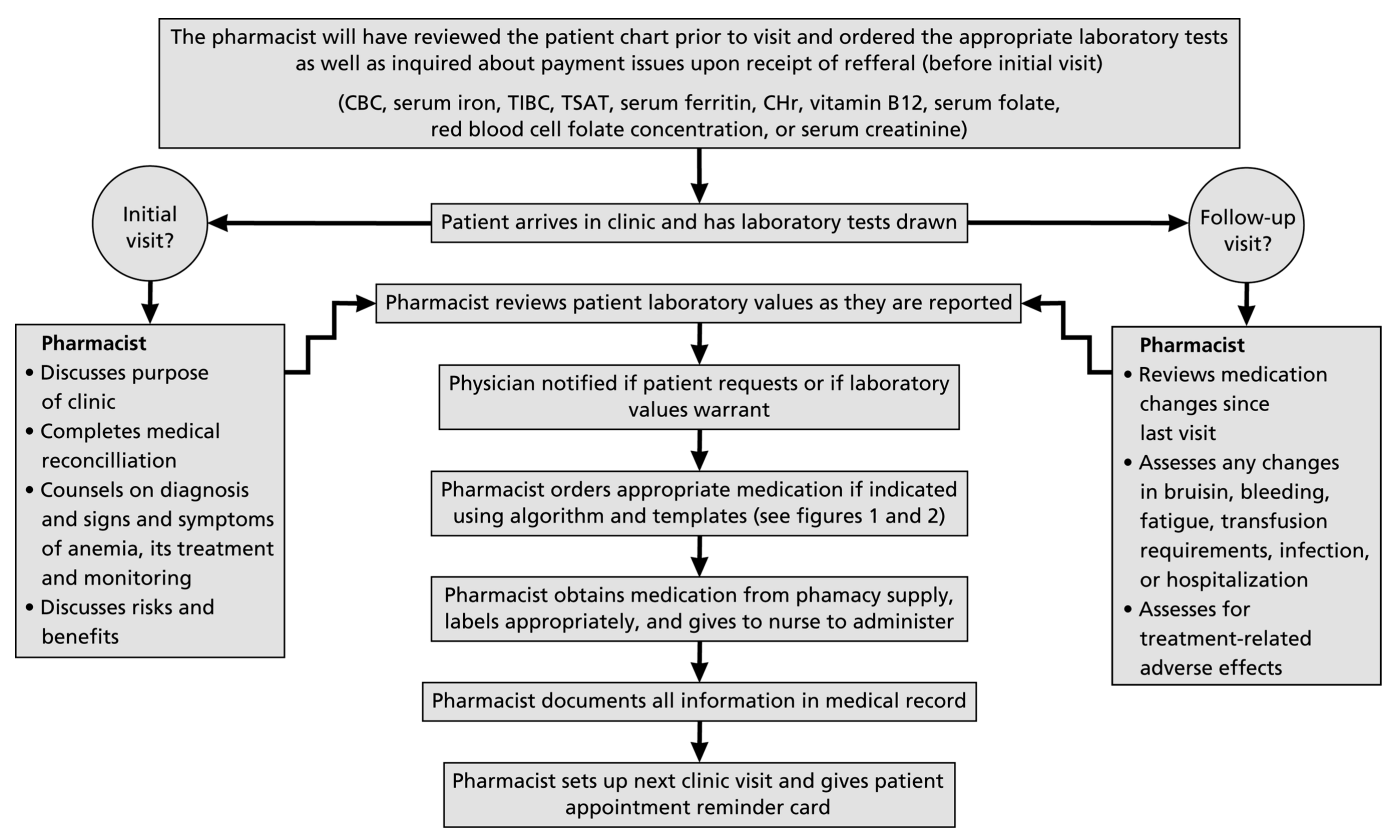

Figure 3 Anemia clinic process and workflow.

Abbreviations: $\mathrm{CBC}$, complete blood count; $\mathrm{CHr}$, reticulocyte hemoglobin content; $\mathrm{TIBC}$, total iron-binding capacity; TSAT, transferrin saturation.

addition, in allowing pharmacists to manage one aspect of supportive care for these patients, physicians can focus more time on the diagnosis and treatment of cancer.

\section{Disadvantages of the Clinic Model}

Despite the clinical and financial justification of pharmacist involvement in the management of anemia therapy, the current nationwide pharmacist shortage may make hiring a pharmacist for this role difficult. However, encouraging other pharmacists to help physicians create institution-specific treatment algorithms and templates is still worthwhile for improving treatment effectiveness, decreasing adverse effects, and increasing reimbursement of ESA therapy.

\section{Conclusion}

This article presents clinical and financial justification for establishing a pharmacist-managed anemia clinic as a way to optimize the management of CIA in hematology-oncology patients undergoing ESA therapy.

\section{References}

1. Ludwig H, Van Belle S, Barrett-Lee P, et al. The European Cancer in Anaemia Survey (ECAS): a large, multinational, prospective survey defining the prevalence, incidence, and treatment of anaemia in cancer patients. Eur J Cancer 2004;40:2293-2306.

2. Rodgers GM, Becker PS, Bennett CL, et al. NCCN Clinical Practice Guidelines in Oncology: Cancer- and Treatment-Related Anemia, version 2.2008. Available at: http://www.nccn.org/professionals/ physician_gls/PDF/anemia.pdf. Accessed April 11, 2008.

3. Auerbach M, Ballard $\mathrm{H}$, Trout JR, et al. Intravenous iron optimizes the response to recombinant human erythropoietin in cancer patients with chemotherapy-related anemia: a multicenter, open-label, randomized trial. J Clin Oncol 2004;22:1301-1307.

4. Henry DH, Dahl NV, Auerbach M, et al. Intravenous ferric gluconate significantly improves response to epoetin alfa versus oral iron or no iron in anemic patients with cancer receiving chemotherapy. Oncologist 2007;12:231-242.

5. Brugnara C, Colella GM, Cremins JC, et al. Effects of subcutaneous recombinant human erythropoietin in normal subjects: development of decreased reticulocyte hemoglobin content and iron-deficient erythropoiesis. J Lab Clin Med 1994;123:660-667.

6. Bamgbola OF, Kaskel F. Role of folate deficiency on erythropoietin resistance in pediatric and adolescent patients on chronic dialysis. Pediatr Nephrol 2005;20:1622-1629.

7. Breen CP, Macdougall IC. Correction of epoetin-resistant megaloblastic anaemia following vitamin B12 and folate administration. Nephron 1999;83:374-375.

8. Gabrilove JL, Cleeland CS, Livingston RB, et al. Clinical evaluation of once-weekly dosing of epoetin alfa in chemotherapy patients: improvements in hemoglobin and quality of life are similar to threetimes-weekly dosing. J Clin Oncol 2001;19:2875-2882.

9. Schwartzberg LS, Yee LK, Senecal FM, et al. A randomized comparison of every-2-week Darbepoetin alfa and weekly epoetin alfa for the treatment of chemotherapy-induced anemia in patients with breast, lung, or gynecologic cancer. Oncologist 2004;9:696-707.

10. Procrit [package insert]. Raritan, NJ: Ortho Biotech Products, L.P.; 2005. 
Gilreath et al.

11. Aranesp [package insert]. Thousand Oaks, CA: Amgen Inc.; 2006.

12. Hedenus $M$, Birgegård $G$, Näsman $P$, et al. Addition of intravenous iron to epoetin beta increases hemoglobin response and decreases epoetin dose requirement in anemic patients with lymphoproliferative malignancies: a randomized multicenter study. Leukemia 2007;21:627-632.

13. Bastit L, Vandebroek A, Altintas S, et al. Randomized, multicenter, controlled trial comparing the efficacy and safety of darbepoetin alpha administered every 3 weeks with or without intravenous iron in patients with chemotherapy-induced anemia. J Clin Oncol 2008; 26:1611-1608.

14. Pedrazzoli P, Farris A, Del Prete S, et al. Randomized trial of intravenous iron supplementation in patients with chemotherapy-related anemia without iron deficiency treated with darbepoetin alpha. J Clin Oncol 2008;26:1619-1625.

15. Auerbach M, Henry DH. Increased importance of intravenous iron in chemotherapy-induced anemia. J Clin Oncol 2007;25:2145-2146.

16. Premier's Perspective Comparative Database [database online]. Charlotte, NC: Premier Inc.

17. Leyland-Jones B. Breast cancer trial with erythropoietin terminated unexpectedly. Lancet Oncol 2003;4:459-460.

18. Henke M, Laszig R, Rübe C, et al. Erythropoietin to treat head and neck cancer patients with anaemia undergoing radiotherapy: randomized, double-blind, placebo-controlled trial. Lancet 2003; 362:1255-1260

19. Wright JR, Ung YC, Julian JA, et al. Randomized, double-blind, placebo-controlled trial of erythropoietin in non-small-cell lung cancer with disease-related anemia. J Clin Oncol 2007;25: 1027-1032

20. $\overline{\text { Hedenus } M}$, Adriansson M, San Miguel J, et al. Efficacy and safety of darbepoetin alfa in anaemic patients with lymphoproliferative malignancies: a randomized, double-blind, placebo-controlled study. Br J Haematol 2003;122:394-403.

21. Bennett CL, Silver SM, Djulbegovic B, et al. Venous thromboembolism and mortality associated with recombinant erythropoietin and darbepoetin administration for the treatment of cancerassociated anemia. JAMA 2008;299:914-924.

22. Wilkinson J. Describing the usage patterns and outcomes of hematopoietic agents at the Huntsman Cancer Institute. Presented at the Western States Residency Conference; May 2004; Asilomar, CA.

23. Kuo GM, Buckley TE, Fitzsimmons DS, Steinbauer JR. Collaborative drug therapy management services and reimbursement in a family medicine clinic. Am J Health Syst Pharm 2004;61:343-354.

24. Ansell J, Hirsh J, Poller L, et al. The pharmacology and management of the vitamin K antagonists: the Seventh ACCP Conference on Antithrombotic and Thrombolytic Therapy. Chest 2004;126(3 Suppl):204S-233S

25. Gray DR, Garabedian-Ruffalo SM, Chretien SD. Cost-justification in a clinical pharmacist-managed anticoagulation clinic. Ann Pharmacother 2007;41:496-501.
26. Adamson R, Baribeault D, Griffith N, et al. Contemporary growth factor management: three institutional perspectives. Therapeutic Insights and Review 2006;41(Suppl 1):1-14.

27. Glaspy J, Bukowski R, Steinberg D, et al. Impact of therapy of epoetin alfa on clinical outcomes in patients with nonmyeloid malignancies during cancer chemotherapy in community oncology practice: Procrit Study Group. J Clin Oncol 1997;15:1218.

28. Cella D. The Functional Assessment of Cancer Therapy-Anemia (FACT-An) Scale: a new tool for the assessment of outcomes in cancer anemia and fatigue. Semin Hematol 1997;34(Suppl 2):13-19.

29. Groopman JE, Itri LM. Chemotherapy-induced anemia in adults: incidence and treatment. J Natl Cancer Inst 1999;91:1616-1634.

30. Lee M. Basic Skills in Interpreting Laboratory Data. Bethesda, MD: American Society of Health-System Pharmacists, Inc.; 2004.

31. Beutler E, Hoffbrand AV, Cook JD. Iron deficiency and overload. Hematology 2003;1:40-61.

32. KDOQI Clinical Practice Guidelines and Clinical Practice Recommendations for Anemia in Chronic Kidney Disease. Am J Kidney Dis 2006;47(5 Suppl 3):S11-145.

33. INFeD [package insert]. Morristown, NJ: Watson Pharmaceuticals, Inc.; 2001

34. Anuradha S, Singh NP, Agarwal SK. Total dose infusion iron dextran therapy in predialysis chronic renal failure patients. Ren Fail 2002;3:307-313.

35. Auerbach M, Chaudry M, Goldman H, et al. Value of methylprednisolone in prevention of arthralgia-myalgia syndrome associated with total dose infusion of iron dextran: a double-blind, randomized trial. J Lab Clin Med 1998;131:257-260.

36. Ferrlecit [package insert]. Florham Park, NJ: Schein Pharmaceuticals, Inc.; 2001.

37. Venofer [package insert]. Shirley, NY: American Regent Laboratories, Inc.; 2001.

38. Chandler $\mathrm{G}$, Harchowal J, Macdougall IC. Intravenous iron sucrose: establishing a safe dose. Am J Kid Dis 2001;38:988-991.

39. Deicher R, Ziai F, Cohen G, et al. High-dose parenteral iron sucrose depresses neutrophil intracellular killing capacity. Kidney Int 2003;64:728-736.

40. Silverstein SB, Rodgers GM. Parenteral iron therapy options. Am J Hem 2004;76:74-78.

41. Folic acid tablets USP $1 \mathrm{mg}$ [package insert]. Corona, CA: Watson Laboratories, Inc.; 2005.

42. Schiffl $\mathrm{H}$, Lang S. Folic acid deficiency modifies the haematopoietic response to recombinant human erythropoietin in maintenance dialysis patients. Nephrol Dial Transplant 2006;21:133-137.

43. Breen CP, Macdougall IC. Correction of epoetin-resistant megaloblastic anaemia following vitamin B12 and folate administration. Nephron 1999;83:374-375.

44. Kuzminski AM, Del Giacco EJ, Allen RH, et al. Effective treatment of cobalamin deficiency with oral cobalamin. Blood 1998;92: 1191-1198. 